\title{
Research and Practice on the Construction of Excellent Courses for Applied Undergraduate Majors-Taking the Course Construction of Engineering Mechanics as an Example
}

\author{
Lin Ran \\ Yunnan Technology Business College, Yunnan, China, 651701
}

Keywords: Application-oriented; quality courses; construction

\begin{abstract}
The construction of excellent courses is an important guarantee to improve the teaching quality, deepen the reform and achieve the training objectives of colleges and universities. It is also the need to build high-level universities. Excellent course construction is by no means a simple construction of teaching materials or a simple "curriculum design", but a real system quality project.
\end{abstract}

In order to strengthen the teaching construction, deepen the teaching reform and improve the teaching quality of colleges and universities, the Ministry of Education has issued the Notice of the Ministry of Education on Starting the Construction of Excellent Courses in the Teaching Quality and Teaching Reform Project of Colleges and Universities and the Implementation Measures for the Construction of National Excellent Courses. Since the mid-1990s, China began to promote the reform of curriculum system, teaching content and methods. At present, many achievements have been made and a large number of excellent courses have been built. In response to the call of the Ministry of Education, colleges and universities have launched curriculum construction according to their own characteristics, deepened teaching reform, and contrived for a new climax of quality curriculum construction, and accordingly achieved very good results.

\section{Establishing the basis of excellent courses}

\subsection{Choosing excellent courses according to training objectives}

Different training objectives have different knowledge points and ability points. To cultivate applied talents, we must take the training of skills application ability and basic quality as the main line, so that enthusiastically knowledge, knowledge application ability and quality can develop in an all-round and coordinated way. When choosing a course as a top-quality course, we should understand the training objectives and directions of each specialty, and determine whether it is the goal of top-quality course construction according to its close connection with the target training and employment orientation and its status and role. 


\subsection{Selecting top-quality courses according to the role of courses in the professional curriculum system}

According to the training objectives, the knowledge system structure of various specialties is described according to "knowledge field - knowledge unit - knowledge point"; referring to the experience of domestic and foreign universities, and combining with the demand of talent market, the curriculum system of many specialties is constructed. The curriculum system should consist of courses scattered in different semesters to accomplish different training tasks. When choosing a course as a top-quality course, we should understand the role and status of the course in the curriculum system. According to the status and role of the course, it is determined whether it is the goal of the construction of quality courses.

For example, this course is a basic course, is an important basis for learning follow-up courses, and can train demonstrability to use their brains and solve practical engineering problems, which can be classified as a top-quality course; and if this course is a professional course, it is a core course integrating the knowledge and technology of this major, and it is also a skill course badly needed by the talent market, it can also be classified as a top-quality course.

\section{Establish the orientation of curriculum in professional training objectives and curriculum construction objectives}

According to the different requirements of the specialty, different teaching designs and content organizations are carried out to ensure the teaching needs of each specialty. The goal of this course is: to cultivate demonstrability to simplify simple engineering problems into mechanical models, to abstractly summarize and define the mechanical phenomena in nature and engineering according to the basic concepts and principles of mechanics. Analysis, logical thinking and judgment ability to make correct judgments, cultivate studentships in material mechanical properties testing and stress analysis testing, cultivate students' self-study ability, computer application ability and ability to solve practical engineering problems; from the quality, cultivate instrumentality of scientific research through theoretical analysis, scientific experiments and computer analysis and other methods. Through simplified induction, Abstract modeling, analysis and synthesis, the quality of solving engineering problems, innovative consciousness and the spirit of dedication to science.

\section{Strengthen the Construction of Teachers}

Table1.Educational background of Teachers

\begin{tabular}{|l|c|c|c|}
\hline & Undergraduate & Master degree student & $\begin{array}{l}\text { Doctor degree } \\
\text { student }\end{array}$ \\
\hline under 40 years old & 5 & 2 & 1 \\
\hline young teachers & 15 & 10 & 5 \\
\hline
\end{tabular}

Young teachers are the backbone of the sustainable development of curriculum construction. Therefore, in the course construction, great importance is attached to the training of young teachers. The teaching and research department organizes young teachers to study the theory and experience of educational reform and formulates a strict training program for young teachers. It guides young teachers. Every young teacher has an old teacher to help them understand and master each teaching link. Only after the course group test can young teachers walk onto the platform and be independent. Teaching is offered. Course group leaders and old teachers also regularly attend classes with young teachers. In view of the existing problems in classroom teaching, timely corrections are given to help them improve the quality of teaching. The Curriculum Group actively encourages and supports 
young and middle-aged teachers to study for degrees in-service and improve their professional level. As shown in Table1.

\section{Teaching methods and means}

The research group has always attached great importance to the improvement of teaching methods and teaching means, with the guiding ideology of "strengthening foundation, emphasizing ability, cultivating quality and highlighting innovation", and the combination of classical and modern curriculum contents. In order to stimulate nonadministrative and creativity in learning, we adopt a variety of teaching forms which combine traditional teaching, heuristic teaching and multimedia teaching. For this purpose, as shown in Figure 1, the following aspects of work have been done in teaching:

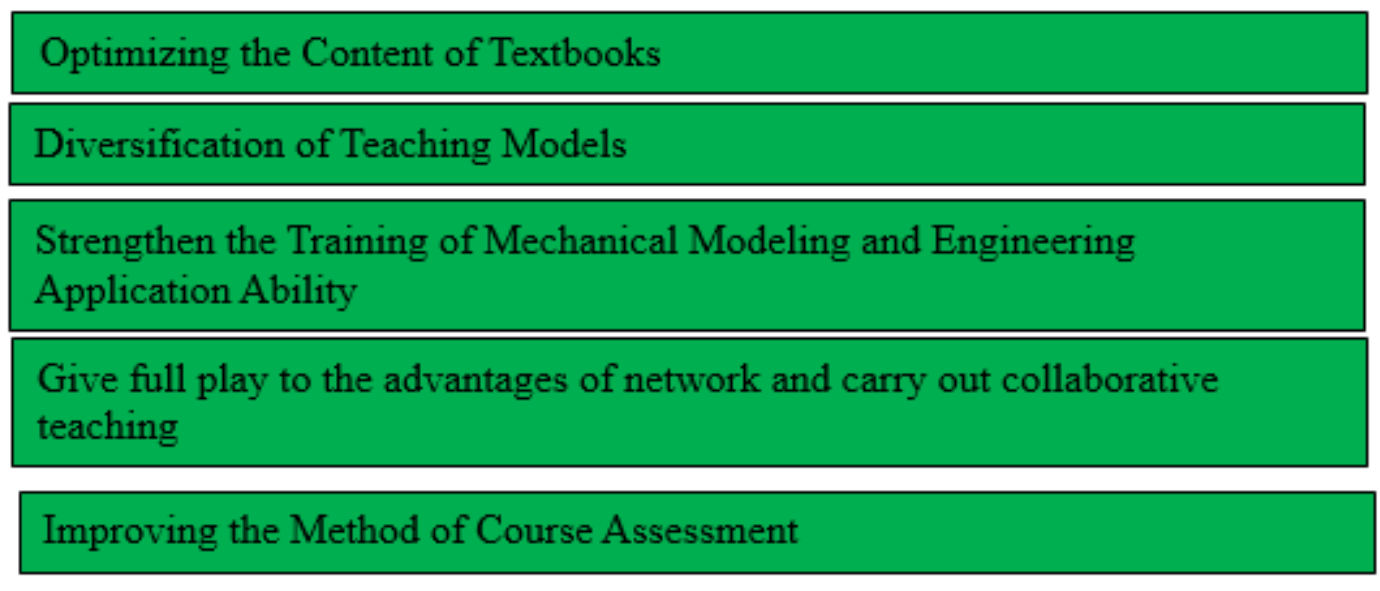

Figure 1. Teaching methods and means

\subsection{Optimizing the content of textbooks}

Engineering Mechanics should embody the complete theoretical system of this course and the strong practical links closely related to engineering practice. The content of the textbook should include three modules: basic module, Application module and extended module. According to the comprehensive needs of teaching and learning, the members of the project team published the first and second volumes of Engineering Mechanics to meet the teaching needs of different majors and different hours.

\subsection{Diversification of teaching models}

Because most students lack the perceptual knowledge of Engineering practice, they are often not good at linking the course content with engineering and production practice. Using multimedia courseware teaching, the actual structure of engineering can be "moved into" classroom, so that students can be exposed to the real "engineering environment", deepen the impression of linking engineering practice, and stimulate uninteresting in learning. At the same time, in the classroom teaching, we can adopt a variety of teaching modes, such as classroom teaching method, problem teaching method, self-study discussion method, guidance induction method and case teaching method, to develop studentship potential, cultivate their comprehensive ability, fully mobilize students' enthusiasm for learning, and enhance competitiveness. 


\subsection{Strengthen the training of mechanical modeling and engineering application ability}

The basic requirement for engineering students is to apply the principles of mechanics to solve practical engineering problems. The teaching content should be conducive to the cultivation of superintending consciousness and the improvement of their mechanical application ability. The teaching mode of large assignment, small design, small paper writing, reading report, innovative report and case teaching are adopted to improve comprehensive application ability.

The writing of the essay is mainly for students to analyze and demonstrate the mechanics knowledge they have learned through observing the engineering practice and the phenomena they have seen. The first is to combine the content they have learned with the topics given by teachers or students to design on their own. The second is to let students design on their own according to the small designs that have been completed on the spot, and then to discuss and analyze the completed designs so as to improve instabilities. Design ability. Flexible and various teaching methods have brought existentialist into full play, strengthened the ability of mechanical modeling and engineering application, and fostered students' comprehensive ability.

\subsection{Give full play to the advantages of network and carry out collaborative teaching}

Students can make full use of abundant online resources to learn course content, problem-solving guidance, self-study and self-test on the Internet. Teachers can answer questions on the Internet in various ways, flexible and flexible time, which can realize online collaborative teaching and self-fulfilment.

\subsection{Improving the method of course assessment}

Assessment should follow the principle of the whole process of assessment, that is, from the beginning to the end, from the inside to the outside, so as to let students know in advance how to correctly treat the course examination, not for the examination. The contents of experiments, large assignments, small designs, small papers and reading reports can all be taken as part of the assessment. Make the examination system truly embody the principle of emphasizing ability and quality. In addition, we have also made improvements in the way of experimental examination, using the method of combining on-site examination with experimental report results, and adopting the method of combining experimental examination with theoretical examination, that is to say, experimental report results are the main method.

\section{Conclusion}

Over the past few years, we have taken the construction of excellent teaching staff as the core, digitalis and Confirmation Teaching as the guarantee, high-quality talents as the purpose, overall planning and key construction, explored the teaching methods and means in the new period, reformed and improved the existing teaching research results, and studied the application of modern multimedia and electronic teaching plan technology in the curriculum, which has made the curriculum construction a tool. Excellent courses with interactivity, demonstration and advancement.

\section{References}

[1] Song Shenanigan. Details of Mechanics Teaching [J]. Education and Teaching Forum, 2011, (09).

[2] Ye Yuan. Training and Practical Teaching Exploration of Applied Talents in Independent Colleges [J]. Educational Exploration, 2010, (3). 
[3] Wu Rena. Speeding up the Reform and Development of Newly-built Undergraduate Colleges around the Training of Applied Talents [J]. China Higher Education, 2010, (22).

[4] Ding Bosnian. Research on the reform of mechanics curriculum in Higher Vocational Education [J].Journal of Human Polytechnic, 2003, 3(3): 85.

[5] Kong Darkling. Thoughts and Practice on Teaching Reform of Engineering Mechanics [J]. Vocational Education Forum, 2003 (4). 